\title{
Corrigendum: Drosophila Brainbow: a recombinase-based fluorescence labeling technique to subdivide neural expression patterns
}

Stefanie Hampel, Phuong Chung, Claire E McKellar, Donald Hall, Loren L Looger \& Julie H Simpson

Nat. Methods 8, 253-259 (2011); published online 6 February 2011; corrected online 16 February 2011; corrected after print 30 August

2012; corrected after print 3 August 2015

In the version of this article initially published, the sequence reported for the dBrainbow construct was incorrect. The blue fluorescent protein was reported as EBFP2; it is mTFP1. The $\mathrm{mKO} 2$ protein is tagged with a V5 epitope and not a Myc epitope, and the EGFP protein is tagged with HSV, not with V5, as detailed in a previous correction to this paper. The red channel reflects endogenous mKO2 fluorescence, not anti-Myc staining. The $\mathrm{mKO} 2$ protein is produced by a codon-optimized sequence. These errors have been corrected in the HTML and PDF versions of the article, and the correct sequence is provided.

\section{Erratum: Rational design of a high-affinity, fast, red calcium indicator R-CaMP2}

Masatoshi Inoue, Atsuya Takeuchi, Shin-ichiro Horigane, Masamichi Ohkura, Keiko Gengyo-Ando, Hajime Fujii, Satoshi Kamijo, Sayaka Takemoto-Kimura, Masanobu Kano, Junichi Nakai, Kazuo Kitamura \& Haruhiko Bito

Nat. Methods 12, 64-70 (2015); published online 24 November 2014; corrected after print 11 June 2015

In the version of this article initially published, GenBank/EMBL/DDBJ accession codes for R-GECO2L and R-CaMP2 were omitted. These accession codes are KR149061 and KR149062, respectively. The error has been corrected in the HTML and PDF versions of the article.

\section{Erratum: Whole-body immunoPET reveals active SIV dynamics in viremic and antiretroviral therapy-treated macaques}

Philip J Santangelo, Kenneth A Rogers, Chiara Zurla, Emmeline L Blanchard, Sanjeev Gumber, Karen Strait, Fawn Connor-Stroud, David M Schuster, Praveen K Amancha, Jung Joo Hong, Siddappa N Byrareddy, James A Hoxie, Brani Vidakovic, Aftab A Ansari, Eric Hunter \& Francois Villinger

Nat. Methods 12, 427-432 (2015); published online 9 March 2015; corrected after print 11 June 2015

In the version of this article initially published, the first name of Emmeline L. Blanchard was misspelled as Emeline. The error has been corrected in the HTML and PDF versions of the article.

\section{Erratum: Multitarget super-resolution microscopy with high-density labeling by exchangeable probes}

Tai Kiuchi, Makio Higuchi, Akihiro Takamura, Masahiro Maruoka \& Naoki Watanabe Nat. Methods 12, 743-746 (2015); published online 6 July 2015; corrected after print 3 August 2015

In the PDF version of this article initially published, the Acknowledgments section erroneously listed the Uehara Memorial Foundation as a funder twice. The error has been corrected in the PDF version of this article.

\section{Erratum: Power and sample size}

Martin Krzywinski \& Naomi Altman

Nat. Methods 10, 1139-1140 (2013); published online 26 November 2013; corrected after print 26 November 2013; corrected after print 3 August 2015

In the version of this article initially published, the terms "sensitivity" and "specificity" and the related descriptors "sensitive" and "specific" were mistakenly switched in three instances. The errors have been corrected in the HTML and PDF versions of the article. 